\title{
TEORIAS DA APRENDIZAGEM E GESTÃO DO CONHECIMENTO: UM ALINHAMENTO TEÓRICO
}

LEARNING THEORIES AND KNOWLEDGE MANAGEMENT: A THEORETICAL ALIGNMENT

Recebido em 10.06.2013. Aprovado em 30.10.2013

Avaliado pelo sistema double blind review

DOI: http://dx.doi.org/10.12712/rpca.v7i4.293

\section{Donizeti Leandro Souza}

souza.doni@yahoo.com.br

Universidade Federal de Lavras (UFLA) - Departamento de Administração e Economia (DAE) - MG- Brasil.

\section{Jorgiane Suelen Sousa}

jsuelenpatos@yahoo.com.br

Universidade Federal de Lavras (UFLA) - Departamento de Administração e Economia (DAE) - MG- Brasil.

\section{Lílian Ferrugini"}

lilianufjf@yahoo.com.br

Universidade Federal de Lavras (UFLA) - Departamento de Administração e Economia (DAE) - MG- Brasil.

\section{André Luiz Zambalde}

zamba@dcc.ufla.br

Universidade Federal de Lavras (UFLA) - Departamento de Administração e Economia (DAE) - MG- Brasil.

\section{Resumo}

O objetivo desse ensaio é apresentar uma investigação entre os pressupostos das teorias da aprendizagem (Behaviorismo, Inteligências Múltiplas e Teoria Construtivista) e sua relação de simetria com as epistemologias da posse e da prática presentes na literatura sobre gestão do conhecimento. Foram identificadas relações de simetria entre a Teoria Behaviorista metodológica com a epistemologia da posse e sua abordagem individual / funcional, na qual o aprendizado muito se assemelha a modelos estruturais de conversão do conhecimento. A Teoria das Inteligências Múltiplas, em conjunto com o Behaviorismo radical, situam-se numa faixa intermediária de alinhamento com as epistemologias da posse e da prática. Por fim, a Teoria Construtivista se aproxima da epistemologia da prática, ao valorizar o aspecto coletivo e dinâmico do conhecimento. Estes achados contribuem para um maior entendimento dos pressupostos das teorias da aprendizagem nas epistemologias da gestão do conhecimento.

Palavras-chave: Teorias da aprendizagem. Epistemologias do conhecimento. Aprendizagem organizacional.

\begin{abstract}
The purpose of this paper is to present an investigation among the assumptions of learning theories (behaviorism, Intelligences Multiple and Constructivist Theory) and its symmetrical relationship to the possession and practice epistemologies found in the literature of knowledge management. They were identified Symmetry relationships between methodological Behaviorist Theory and the epistemology of possession and his individual approach / functional and that learning is very similar to structural models of knowledge conversion. The Multiple Intelligences Theory in conjunction to the radical behaviorism are situated on an intermediate range of alignment to the possession and practice epistemologies. Finally, the Constructivist Theory approaches to the epistemology of practice valuing the collective and dynamic aspect of knowledge. These findings contribute to a greater understanding about assumptions of learning theories in the epistemologies of knowledge management.
\end{abstract}

Keywords: Learning Theories. Knowledge's Epistemologies. Organizational learning. 


\section{Introdução}

Diante da rapidez de mudanças e da alta competitividade no atual cenário organizacional, novas abordagens e estratégias têm surgido nos últimos anos, tendo com foco central, a geração de aprendizados organizacionais e a gestão do conhecimento. 0 modelo mecanicista de Taylor vem dando espaço a novas abordagens interacionistas que vêem o indivíduo, não apenas como uma peça passiva de uma máquina produtiva, mas como um ser dotado de inteligência, capaz de construir o conhecimento e interferir no ambiente de trabalho, dentro de um processo de aprendizagem contínua.

Outro ponto relevante que as organizações começam a desenvolver é o incentivo à criatividade e o cultivo de idéias novas que permitam a renovação de conceitos existentes, surgindo a necessidade de ambientes abertos e propícios à participação de todos na identificação de oportunidades, possibilidades e limites organizacionais. Surge assim, no campo empresarial e acadêmico, uma nova abordagem de gestão, que permita às organizações reinventar o jeito tradicional de gerir negócios, desaprendendo para aprender e aprendendo a desaprender de modo dinâmico, transformando o conhecimento em seu ativo principal (FIALHO et al, 2006).

Para entender a evolução de conceitos sobre as epistemologias de estudos da gestão do conhecimento, torna-se preciso conhecer as bases filosóficas de teorias da aprendizagem humana que surgiram nos últimos tempos, aqui discutidas por meio da Teoria Behaviorista (metodológica/radical), Teoria das Inteligências Múltiplas e Teoria Construtivista, pois fornecem as bases para os processos comportamentais / cognitivos da geração do conhecimento sob diferentes perspectivas. Nesse sentido, o objetivo deste estudo é apresentar uma investigação entre os pressupostos das teorias da aprendizagem (Behaviorismo, Inteligências Múltiplas e Teoria Construtivista) e as relações de simetria com as epistemologias da posse e da prática presentes na literatura sobre gestão do conhecimento.

Visando atender o objetivo proposto, o artigo está dividido em quatro seções. Na primeira parte serão discutidos os conceitos introdutórios da aprendizagem organizacional sob as perspectivas das teorias da aprendizagem (Behaviorismo, Inteligências Múltiplas e Construtivismo). Na segunda parte serão apresentados os principais conceitos da gestão do conhecimento sob as perspectivas e polaridades das epistemologias da posse e da prática. $\mathrm{Na}$ terceira parte será apresentado um alinhamento teórico entre as contribuições das teorias da aprendizagem e suas relações de simetria com as epistemologias da posse e da prática, aproximando conceitos e epistemologias de estudo. Por fim, serão apresentadas as considerações finais deste ensaio teórico, expondo possíveis contribuições, limites e sugestões para novas pesquisas.

\section{Aprendizagem organizacional}

Aprendizado não significa adquirir informações - aprendizado significa aumentar nossa capacidade para agir e alcançar uma evolução sustentada de performance.

Peter Senge (2010)

Nos últimos anos têm se notado um aumento expressivo de trabalhos no campo da gestão do conhecimento e da aprendizagem organizacional como elementos cruciais para a criação de vantagens competitivas sustentáveis (ANTONELLO; GODOY, 2010; BEHR; NASCIMENTO, 2008), surgindo diferentes abordagens sobre os processos de criação, partilha e gestão do 


\section{TEORIAS DA APRENDIZAGEM E GESTÃO DO CONHECIMENTO: UM ALINHAMENTO TEÓRICO}

conhecimento em ambientes organizacionais.

Diversos autores alertam que para ter sucesso as organizações precisam não somente promover mudanças e "acompanhar" as tendências do mercado, elas precisam inovar e reinventar seu jeito de aprender. 0 velho e tradicional método de apagar incêndios deve dar lugar ao novo, em que a organização possa usufruir do capital intelectual de seus membros, cultivando nas pessoas de todos os níveis hierárquicos e departamentos, o comprometimento e a capacidade constante do aprendizado contínuo (SENGE, 2010).

Cória-Sabini (1986) já definia aprendizagem como o processo pelo qual uma atividade tem origem ou é modificada pela reação a uma situação encontrada, desde que as características de mudanças não possam ser explicadas por tendências inatas de respostas, maturação ou estados temporários do organismo. Transmite-se assim, uma ideia de mudança em que um conceito é criado ou alterado pela vivência e experiência de vida, transformando numa mudança de atitude, comportamento, aptidões ou habilidades.

Já Argyris e Schon (1978) afirmam existir dois ciclos de aprendizagem organizacional: ciclo de aprendizado único (single loop learning): o aprendizado assume um caráter operacional, sem mudanças significativas de comportamentos novos; e o ciclo de aprendizado duplo (double loop learning): o aprendizado enfatiza as causas das rotinas organizacionais em processos de experimentação de novas práticas para a construção de conhecimentos relevantes.

Assim, a aprendizagem organizacional passa a assumir todo processo de aquisição e transferência de conhecimentos que podem ser convertidos nos diferentes níveis: individual, grupal e organizacional, que por sua vez, são dependentes de três condições: (1) uma cultura que facilite a aprendizagem, (2) um processo de formação e capacitação, tanto técnica como institucional e, (3) transferências de informações que se convertem em conhecimentos (CASTAÑEDA; Ríos, 2007). A inteligência, a criatividade e o conhecimento das pessoas são os principais recursos a serem desenvolvidos por uma organização aprendente (TAVARES, 2010).

Ao propormos um estudo sobre os processos de aprendizagem organizacional e gestão do conhecimento, torna-se preciso uma breve revisão de conceitos sobre teorias comportamentais / cognitivas da aprendizagem, pois estas auxiliam a entender como as pessoas aprendem e quais condições são necessárias para que isso ocorra. Apesar de essas teorias surgirem fora do contexto organizacional, seu entendimento poderá será útil para explicar as diferentes formas com que o conhecimento vem sendo tratado na literatura organizacional.

Entre as principais correntes de aprendizagem abordada nesse estudo, destacam-se a Teoria Behaviorista (PAVLOV; WATSON; SKINNER; MORGAN), em que o comportamento é controlado por meio de processos de condicionamento; a Teoria das Inteligências Múltiplas (GARDNER), na concepção de diferentes tipos de inteligências que constituem os blocos construtores da inteligência humana, e o Construtivismo (PIAGET; VIGOTSKY), em que as construções de aprendizagem só são possíveis graças à interação do sujeito com seu meio físico e social, numa perspectiva de que o conhecimento e os processos de aprendizagem só podem ser construídos por meio da ação humana, em contextos sociais. A aprendizagem organizacional passa a ser compreendida como um conjunto de processos que se interagem, com foco no surgimento de efeitos positivos para o alcance de conhecimentos diversos e, dessa forma, garantirem efeitos competitivos contínuos. 


\section{Teorias Behavioristas}

A teoria Behaviorista tem suas bases no movimento positivista de causa e efeito como elementos de estudos empíricos (Neufeld; Brust; Stein, 2011; BUENO, 2011). Essa corrente de pensamento ganhou destaque com os estudos de Watson, Pavlov e Skinner, partindo do princípio que os processos de aprendizagem somente são possíveis por meio de estímulos externos e a assimilação de idéias se transfere de um indivíduo a outro através da aquisição de um novo comportamento. Dentre as principais correntes da teoria Behaviorista, destacamse o Behaviorismo metodológico e o Behaviorismo radical.

Segundo Abreu (1988), o objetivo da teoria Behaviorista metodológica é descobrir e analisar possíveis causas do comportamento humano, permitindo a previsão e o controle dos processos de aprendizagem em relações funcionais de causa e efeito. Assim, os princípios que regem o comportamento humano são entendidos como um processo composto por variáveis como: ambiente, estímulo-resposta e contingências, sendo estes imprescindíveis para explicar o aprendizado humano (Neufeld; Brust; Stein, 2011; ABREU, 1988).

Os behavioristas metodológicos acreditavam que todas as pessoas podiam aprender por meio dos mesmos esquemas de reforços e estímulos. 0 processo de aprendizagem consistia em recompensar os comportamentos desejados e punir ou ignorar os indesejáveis. 0 indivíduo era visto como um ser relativamente passivo, recebendo estímulos externos para mudanças de comportamentos condicionados em formas simples de associação (GARDNER, 2000).

Em oposição ao Behaviorismo metodológico, Skinner e seus seguidores cunharam mais tarde o Behaviorismo radical, no qual a mudança de comportamentos humanos passou a ser considerada estritamente ligada à vivência do indivíduo com o meio. 0 desenvolvimento do comportamento passou a ser valorizado através da comunicação verbal, capaz de assumir dois tipos diferentes de controle: o controle aversivo (coercitivo) e o controle positivo (BUENO, 2011; skinner, 2000). O controle aversivo era visto como danoso, ao limitar a capacidade de aprendizagem humana (sujeito clivado e passivo). Já o controle positivo se mostrava um tipo de contingência mais benéfica, pois, promovendo a interação humana por meio de relações sociais, o indivíduo era capaz de modificar e ser modificado pelo meio (FRUTUOSO; CIRINO, 2006).

As Teorias Behavioristas tornam-se úteis para entender os processos de aprendizagem organizacional, em que o uso de condicionamentos (estímulos) podem se tornar uma importante ferramenta de motivação no desenvolvimento de novos aprendizados. Nesta perspectiva, o conhecimento é um bem que cada indivíduo possui e pode transferi-lo a outras pessoas, mesmo que estas não tenham vivenciadas as mesmas experiências (BEHR; NASCIMENTO, 2008; NEWELL et al., 2009; SOUZA-SILVA; DAVEL, 2007). Nesse sentido, o incentivo à criatividade, diálogo, processos decisórios participativos, dentre outras contingências positivas do meio são capazes de interferir e otimizar os processos de aprendizagem.

\section{Teoria das Inteligências Múltiplas}

A Teoria das Inteligências Múltiplas surgiu como crítica ao teste de Q.I. (Quociente de Inteligência) desenvolvido pelo pedagogo e psicólogo francês Alfred Binet, e popularizado nos EUA por Lewis Terman e Robert Yerkes nas décadas de 1920 e 1930. 


\section{TEORIAS DA APRENDIZAGEM E GESTÃO DO CONHECIMENTO: UM ALINHAMENTO TEÓRICO}

Tendo como principal idealizador Howard Gardner, a Teoria das Inteligências Múltiplas ampliou os estudos cognitivos da inteligência humana ao focar na capacidade de solucionar problemas ou elaborar produtos que são importantes em um determinado ambiente ou comunidade cultural (NORUZI; RAHIMI, 2010; GARDNER, 2001; TRAVASSOS, 2001). Apesar da teoria das Inteligências Múltiplas representar uma visão particular sobre a natureza da inteligência, sua contribuição para os processos de ensino-aprendizagem foram largamente utilizados, tornando-se uma abordagem viável para explorar estilos individualizantes de ensino e aprendizagem, assumindo três visões centrais: (1) Identificar formas particulares de aprendizagem; (2) Buscar estratégias para potencializar as habilidades e as inteligências dos indivíduos; (3) Ampliar o conceito de inteligências por meio da diversidade de estruturas cognitivas (ÖZDEMIR; GÜNEYSU; TEKKAYA, 2006).

Diferentemente da teoria Behaviorista, a proposta da Teoria das Inteligências Múltiplas sugere que a mente humana não é como uma lousa em branco que absorve passivamente todos os tipos de informações, ela (a mente) possui uma estrutura inicial e um conjunto de diversos sistemas representacionais, que ao serem ativados, são capazes de construir ou potencializar novos conhecimentos (GARDNER, 2000).

Gardner identificou nove tipos de inteligências, são elas: Verbal-Linguística; LógicoMatemática; Musical; Visual-Espacial; Corporal-Cinestésica; Interpessoal; Intrapessoal; Naturalista e Existencial. O desenvolvimento de cada uma dessas inteligências se baseia em aspectos biológicos e na interação do indivíduo com o meio (NORUZI; RAHIMI, 2010; ROSAS, 2009; ÖZDEMIR; GÜNEYSU; TEKKAYA, 2006). A construção de aprendizados tende a variar de indivíduo para indivíduo, pois os diversos tipos de inteligências assumem capacidades e desempenhos diferentes. Explica-se assim, o surgimento de músicos, poetas, atletas, engenheiros, políticos, etc., cada um desenvolvendo habilidades e competências distintas.

Mas qual a importância dessa teoria para o ambiente organizacional? Segundo Noruzi e Rahimi (2010) a Teoria das Inteligências Múltiplas é importante para mapear as habilidades individuais de cada funcionário, tornando-se possível identificar as potencialidades e as limitações de cada indivíduo na formação de grupos de trabalhos estratégicos, visando melhorar a eficácia organizacional. Complementando esses conceitos, Mattos (2005, p.40) assevera:

Procurar desenvolver a inteligência em que cada pessoa em particular é mais apta é um ato importante para o crescimento do ser humano e de qualquer organização. A empresa em conjunto com seus líderes e seus colaboradores, pode e deve procurar se conhecer bem, a fim de perceber qual suas melhores capacidades, podendo assim fazer com que cada um dê o melhor de si em sua área ou para que sejam remanejados em suas funções, ficando cada um no lugar que melhor pode se desenvolver.

Desta forma, a Teoria das Inteligências Múltiplas contraria os pressupostos da Teoria Behaviorista metodológica de que é possível prever e controlar processos de aprendizados, pois diferentes pessoas apresentam interesses e habilidades distintas e, consequentemente, aprendem de maneiras diversas. Os processos de aprendizagem não devem ser "padronizados", mas sim customizados, de forma que o processo de aprendizagem atenda às particularidades de cada indivíduo, mapeando e maximizando suas competências em favor da coletividade (GARDNER, 2000, 2001). 
Além de estímulos à ativação das estruturas cognitivas por meio da experimentação, a Teoria das Inteligências Múltiplas reconhece que a construção de conhecimentos se forma pelo favorecimento do aspecto cultural e contextual de cada ambiente de trabalho, migrando da perspectiva individual-cognitiva, proposta pelos modelos estruturais do conhecimento, para um caráter prático, em que a aprendizagem não se situa apenas na mente das pessoas, mas principalmente, nas relações sociais entre indivíduos engajados em processos culturais de experimentação-resposta, visando construir ou potencializar novos conhecimentos (SOUZASILVA; DAVEL, 2007; MATTOS, 2005; GARDNER, 2000).

\section{Teoria Construtivista}

O Construtivismo representa uma das teorias da aprendizagem mais influentes dos últimos tempos, pois trouxe profundas mudanças de paradigmas na epistemologia do conhecimento e na teoria da aprendizagem, representando uma visão epistemológica de construção do conhecimento, em que a natureza fundamental do aprendizado se mostra inseparável do contexto histórico e da interação social (APPLEFIELD; HUBER; MOALLEM, 2000).

Tendo como principais idealizadores: Piaget por meio do desenvolvimento biológico do homem com o meio e; Vigotsky com as relações de trocas entre parceiros sociais, através de processos de interação e mediação, o Construtivismo revolucionou os processos de ensinoaprendizagem ao defender que o conhecimento só pode ser construído a partir do envolvimento ativo do indivíduo com o meio. 0 conhecimento não vem pronto, como afirma a Teoria Behaviorista, e nem possui estruturas cognitivas biológicas, como afirma a Teoria das Inteligências Múltiplas, o conhecimento é dinâmico, construído a partir da vivência e das relações estabelecidas em diferentes processos de aprendizagem (STANO; LEITE, 2001).

Assim, todo conhecimento novo é construído porque se retira essa novidade das ações praticadas e não das ações meramente observáveis, como defendido pelas Teorias Behavioristas e Inteligências Múltiplas (MATTOS, 2005; GARDNER, 2000). Isto nos mostra que não basta apenas apresentar o conteúdo para que o indivíduo aprenda, é preciso criar situações para se estabelecerem relações práticas, desenvolvendo relações entre relações, de modo que as construções cognitivas sejam renovadas e reinventadas para o surgimento de novos aprendizados. Só assim se alcança a compreensão de um novo conhecimento.

$\mathrm{Na}$ Teoria Construtivista, o sujeito é ativo em todas as etapas de sua vida. Ele procura conhecer e compreender o que se passa à sua volta. Diante de um desafio, de um estímulo ou de uma lacuna no conhecimento, o sujeito se desequilibra intelectualmente, fica curioso, instigado, motivado, e através de assimilações, procura restabelecer o equilíbrio que é sempre dinâmico, pois é alcançado por meio de ações físicas e/ou mentais (SILVEIRA, 2004).

A Teoria Construtivista é, portanto, interacionista em relações de sujeito-objeto como numa estrutura bipolar, cujos elementos são inseparáveis (VIGOTSKY, 1988). Não há sujeito sem objeto e não há objeto sem sujeito que o construa. 0 sujeito não está simplesmente situado no mundo, mas o meio (o objeto) entra como parte integrante do próprio sujeito, como matéria de conteúdo cognitivo e histórico.

E qual a contribuição dessa teoria para as organizações? Stano e Leite (2001) asseveram que a Teoria Construtivista oferece suporte de trabalho e de produção nas organizações (seja conhecimento estratégico, técnico ou geral). Mesmo que já exista um corpus elaborado pela empresa (sua cultura organizacional, seus valores implícitos, seus artifícios de gestão), o 


\section{TEORIAS DA APRENDIZAGEM E GESTÃO DO CONHECIMENTO: UM ALINHAMENTO TEÓRICO}

sujeito que nela ingressa, assimila esse conhecimento num movimento de construção por assimilação e acomodação, reestruturando conceitos e linguagens prévias e realizando sínteses sucessivas. Cabe destacar que nesta apropriação do aprendiz/profissional, o que vai definir a qualidade do conhecimento adquirido e processado é a configuração do ambiente de trabalho, ou seja, uma organização que valorize a autonomia e o estabelecimento de relações mais democráticas, pois facilita e qualifica o acesso do sujeito ao objeto de conhecimento (seja ele o funcionamento do setor, o processo de produção, distribuição de produtos, etc.).

Desta forma, a epistemologia construtivista representa uma tentativa de entender os processos pelos quais as pessoas aplicam o conhecimento adquirido na prática, fazendo com que o desenvolvimento de competências seja visto como algo dinâmico, enraizado na ação e prática social (NEWELL et al., 2009). Isso torna-se importante nos tempos atuais, pois está enraizado na mudança contínua de atitudes e comportamentos do ambiente organizacional, deixando de ser um ambiente mecanizado para assumir um ambiente ativo, capaz de gerar conhecimentos e aprendizados em favor da própria organização.

Antonello e Godoy (2010) corroboram esses conceitos ao afirmarem que sob a ontologia construcionista, a aprendizagem organizacional assume uma conversação aberta entre indivíduos através da participação e da reflexividade, analisadas sobre uma perspectiva multiparadigmática de diversos saberes: fenômeno comportamental, sociocultural, cognitivo, reflexivo, emocional e experiencial. É uma perspectiva baseada em práticas, pois emerge de relações e interações de pessoas com elementos sociais e materiais envolvidos em diferentes contextos particulares. A partir das definições expostas, julga-se importante discutir e analisar os conceitos de gestão do conhecimento para buscar relações epistemológicas às teorias da aprendizagem apresentadas.

\section{Gestão do conhecimento}

O termo conhecimento pode assumir diversos significados: informação, cognição, percepção, ciência, experiência, qualificação, competência, habilidade prática, capacidade e aprendizado. Assim, termos teóricos aparentemente "iguais" podem assumir significados práticos distintos, tornando o conhecimento, um termo complexo de ser explicado pelo conjunto de atributos e epistemologias a ele mencionado (Sveiby, 1998).

Nesse estudo, considera-se conhecimento, o conjunto de informações que constituem uma crença verdadeira justificada a uma habilidade técnica desejada (competência). Conhecimento é entendido como o processo pelo qual empresas exploram habilidades significativas de seus membros, incorporando teoria e prática através de contextos, pessoas e experiências em processos de aprendizagem (NEWELL et al., 2009; Nonaka, 2007; MCINERNEY, 2002).

Por gestão do conhecimento, entende-se o conjunto de técnicas e ferramentas facilitadoras dos processos de criação e compartilhamento de conhecimentos relevantes, buscando desenvolver vantagens competitivas. Sua aplicação visa modificar comportamentos organizacionais para um novo jeito de administrar, agregando valor e diferencial a processos, produtos ou serviços (Nonaka, 2007; FIALHO et al., 2006; Swan, 1999).

Percebe-se que a aprendizagem organizacional figura na gestão do conhecimento como um construto fundamental, promovendo debates sobre as diferentes formas de gerir conhecimentos e construir sistemas de aprendizagem mais eficientes. Dentre esses debates, 
duas importantes correntes de pensamento têm se destacado na literatura sobre gestão do conhecimento: a epistemologia da posse (NONAKA; KONNO, 1998; NONAKA; TAKEUCHI, 1997; SPENDER, 1996; BLACKLER, 1995; ACKOFF, 1989;) e a epistemologia da prática (Feldman; Orlikowski, 2011; Behr; Nascimento, 2008; CAMPOS, 2007; SOUZA-SILVA; DAVEL, 2007; McInerney, 2002; COOK; BROWN, 1999; McAdam; McCreedy, 1999) em perspectivas distintas de como o conhecimento deve ser gerido no ambiente organizacional.

A diversidade dessas epistemologias se esforça em explicar a amplitude de conceitos, principalmente o corpus e as dimensões da aprendizagem organizacional, tornando-se necessário uma definição dos principais pontos dessas perspectivas de estudo.

\section{Epistemologia da Posse}

Trata-se de uma dimensão funcionalista baseada em processos de conversão, geração, codificação e disseminação do conhecimento. Nessa perspectiva o conhecimento é um bem que cada indivíduo possui e pode transferi-lo a outras pessoas a partir de condicionamentos e construções cognitivas, podendo ser codificado e transmitido fora de contextos sociais onde foi gerado (NEWELL et al., 2009; SOUZA-SILVA; DAVEL, 2007).

A epistemologia da posse enfatiza as perspectivas estruturais do conhecimento e seus aspectos cognitivos, por meio de formatos tácitos e explícitos. 0 formato tácito seria todo tipo de conhecimento baseado em intuições, subjetividades, experiências, percepções e sistemas de idéias, internalizados a partir da assimilação de cada indivíduo. Já o formato explícito seria todo conhecimento passível de codificação e articulação, possíveis de serem externalizados a partir de símbolos, códigos, figuras ou expressão verbal, o que o torna fácil de ser transferido e reutilizado (Davenport; Prusak, 2003).

Segundo Cook e Brown (1999), a epistemologia da posse tende a privilegiar o conhecimento explícito ao invés do conhecimento tácito, pois o conhecimento é valorizado como recurso se codificado e armazenado para reutilização, sendo esta uma das principais preocupações dos modelos estruturais da posse: converter conhecimentos tácitos (subjetivos) em explícitos (codificados). Ademais, nota-se por esta epistemologia de estudo, uma valorização do conhecimento individual ao invés do coletivo, uma vez que o aspecto social é pouco valorizado como locus do conhecimento.

Dentre as principais estruturas e modelos da epistemologia da posse, destacam-se: a Hierarquia do conhecimento (ACKOFF, 1989); o modelo SECI (NONAKA; Takeuchi, 1997); o Modelo "BA" (NONAKA; KONNO, 1998); o lócus do conhecimento (SPENDER, 1998) e o Modelo de organizações e tipos de conhecimentos (BLACKLER, 1995).

\section{Epistemologia da prática}

Já os pesquisadores da epistemologia da prática defendem que a produção de novos conhecimentos somente é possível através da interação dinâmica com o mundo físico e social por meio da ação, e não através de processos simplistas de conversão de conhecimentos tácitos em explicítos, conforme defende a epistemologia da posse (COOK; BROWN, 1999). A preocupação está em estabelecer contextos favoráveis a processos e práticas de diferentes grupos e interesses sociais (NEWELL et al., 2009). 


\section{TEORIAS DA APRENDIZAGEM E GESTÃO DO CONHECIMENTO: UM ALINHAMENTO TEÓRICO}

A epistemologia da prática tem sido influenciada por teóricos sociais como Pierre Bourdieu, Anthony Giddens, Michel Foucault e Nietzsche, além de teóricos da sociologia empírica, de estudos culturais e da antropologia como Harold Garfinkel, Judith Butler e Bruno Latour em teorias que tratam da prática social.

Diferente da epistemologia da posse, essa perspectiva de estudo valoriza o conhecimento coletivo ao invés do individual, tratando o aprendizado organizacional como um processo sócio-prático do conhecimento (ANTONELLO; GODOY, 2010; CAMILLIS; ANTONELLO, 2010; SOUZA-SILVA; DAVEL, 2007). 0 foco está no que as pessoas fazem, tentando entender os processos pelos quais, pessoas e organizações, constroem aprendizados por meio da prática, sendo os processos de criação do conhecimento entendidos como uma habilidade enraizada em ações e práticas sociais (NEWELL et al., 2009).

Para que a criação de novos conhecimentos contribua aos processos de aprendizagem organizacional, três importantes fatores tornam-se importantes: (1) construção de um ambiente favorável à aprendizagem, (2) processos de aprendizagem práticas, e (3) comportamentos da liderança no suporte à criação de conhecimentos coletivos (Garvin; Edmondson; gino, 2008; Pedraja-Rejas; Rodriguez-Ponce, 2008), sendo esses fatores responsáveis por ampliar, em toda a organização, o conhecimento criado nos níveis individual, grupal e organizacional, construindo assim, uma rede de conhecimentos organizacionais (Castañeda; Ríos, 2007; Swan et al., 1999).

Diante das diversas perspectivas de estudos envolvidos nesse processo, como: fenômeno comportamental, sociocultural, cognitivo, reflexivo, emocional e experiencial, a epistemologia da prática se apresenta como a abordagem que melhor contempla uma multiplicidade de perspectivas, pois emerge das interações entre pessoas com elementos sociais e materiais envolvidos em contextos particulares (ANTONELLO; GODOY, 2010).

Embora os teóricos da prática enfatizam diferentes aspectos relacionais e lógicas distintas, todas geralmente concordam com um conjunto chave de teorizações: 1) as ações situadas decorrem na produção da vida social; 2) os dualismos são rejeitados como uma forma de teorização e; 3) as relações de constituição mútua são importantes, sendo esses princípios interdependentes (Feldman; Orlikowski, 2011). Demonstra-se haver certa simetria de pensamentos que convergem a um interesse comum no cotidiano (rotinas organizacionais) e no mundo da vida, sendo influenciados por interpretações ou culturas voltadas à teoria social (Reckwitz, 2002). O Quadro 1 apresenta uma síntese dos principais pontos de divergências entre as epistemologias da posse e da prática. 
Quadro 1

\section{Resumo das perspectivas sobre as Epistemologias do conhecimento}

\begin{tabular}{|c|c|c|}
\hline Perspectivas & Epistemologia da posse & Epistemologia da prática \\
\hline Visão de vida social & $\begin{array}{l}\text { Indivíduos navegam em um } \\
\text { mundo objetivo externo por } \\
\text { meio de processos cognitivos }\end{array}$ & $\begin{array}{l}\text { Práticas centradas em aspectos (humanos e } \\
\text { não humanos) organizadas em torno de } \\
\text { entendimentos práticos compartilhados }\end{array}$ \\
\hline Visão do Conhecimento & $\begin{array}{l}\text { Conhecimento como uma } \\
\text { entidade cognitiva - um } \\
\text { recurso a ser acumulado, } \\
\text { capturado e transferido }\end{array}$ & $\begin{array}{l}\text { Saber como prática - } \\
\text { constituído por interconexões práticas } \\
\text { através da ação social }\end{array}$ \\
\hline Local do conhecimento & $\begin{array}{l}\text { Incorporado na cabeça e nas } \\
\text { habilidades de } \\
\text { indivíduos/organizações }\end{array}$ & $\begin{array}{l}\text { Incorporado e investido de práticas } \\
\text { (interação com o meio) }\end{array}$ \\
\hline $\begin{array}{l}\text { Conhecimento e } \\
\text { desempenho } \\
\text { organizacional }\end{array}$ & $\begin{array}{l}\text { Conhecimento relacionado a } \\
\text { um bom desempenho funcional }\end{array}$ & $\begin{array}{c}\text { Relação entre conhecimento e desempenho } \\
\text { organizacional mediado } \\
\text { através da prática }\end{array}$ \\
\hline $\begin{array}{l}\text { Foco da gestão do } \\
\text { conhecimento }\end{array}$ & $\begin{array}{c}\text { Transferir ou converter } \\
\text { conhecimentos tácitos em } \\
\text { explícitos, em níveis individual } \\
\text { e/ou organizacional }\end{array}$ & $\begin{array}{l}\text { Construir conhecimentos através de } \\
\text { práticas que se sobrepõem }\end{array}$ \\
\hline Objetivos & $\begin{array}{c}\text { Capturar / transferir } \\
\text { conhecimentos usando } \\
\text { Tecnologias da Informação }\end{array}$ & $\begin{array}{l}\text { Gerar conhecimentos através da criação de } \\
\text { comunidades de prática }\end{array}$ \\
\hline
\end{tabular}

Fonte: Adaptado de Newell et al (2009, p.18).

A partir do exposto, identificam-se divergências entre as epistemologias da posse e da prática, indicando interpretações distintas sobre a criação e difusão do conhecimento. No entanto é possível identificar relações epistemológicas convergentes entre as diferentes perspectivas da gestão do conhecimento com as Teorias Behavioristas, Inteligências múltiplas e Construtivistas, sendo necessário um alinhamento teórico dessas perspectivas na tentativa de estabelecer relações de simetria entre as diversas perspectivas da aprendizagem com a gestão do conhecimento.

\section{Alinhamento teórico: aprendizagem e conhecimento}

Percebe-se que a temática ligada à gestão do conhecimento tem sido influenciada por estudos pioneiros de Cyert e March (1963) sobre a aprendizagem organizacional, em teorias que ao longo dos anos contribuíram para o entendimento de processos cognitivos do conhecimento e da inteligência humana. Conhecimento e aprendizagem são vistos como ações complementares, em que processos de aprendizagem levam a novos conhecimentos, assim como novos conhecimentos podem levar a processos de aprendizagem (BINOTTO, 2005).

Diversas teorias da aprendizagem, como o Behaviorismo, o Construtivismo e a Teoria das Inteligências Múltiplas, podem apresentar simetrias de compreensão nas epistemologias de estudos da gestão do conhecimento. Apesar de apresentarem pontos de vistas diferentes 


\section{TEORIAS DA APRENDIZAGEM E GESTÃO DO CONHECIMENTO: UM ALINHAMENTO TEÓRICO}

entre si, essas teorias se complementam e auxiliam sua utilização em ambientes diferentes, onde não existe um modelo ideal e padrão, mas um modelo que se adapte melhor a cada tipo de objetivo e cultura organizacional.

Num primeiro momento ao se analisar os principais fundamentos da Teoria Behaviorista em sua perspectiva metodológica, percebe-se certa simetria com a epistemologia da posse, uma vez que o aprendizado se dá por meio da transferência de ideias de um indivíduo a outro em processos de conversão de conhecimentos tácitos / explícitos (ver modelo SECI de Nonaka e Takeuchi, 1997), se caracterizando como uma abordagem funcional, em que os processos de aprendizagem humana são passiveis de "previsão" e "manipulação", considerando o aprendizado e a construção de conhecimento como algo passivo (GARDNER, 2000).

Já o Behaviorismo radical também se assemelha aos modelos funcionais interacionistas da epistemologia da posse (ver modelo "BA" de Nonaka e Konno, 1998) que começam a considerar o indivíduo moldando e sendo moldado pelo meio, em processos de interações positivas e dinâmicas. 0 conhecimento começa a se distanciar da objetividade por meio da comunicação verbal (diálogo) e da mudança de comportamentos construídos em relações sociais (SKINER, 2000; FRUTUOSO; CIRINO, 2006). Em conjunto com a Teoria das Inteligências Múltiplas, que também considera a interferência do meio na construção de novos aprendizados, essas teorias (Behaviorismo radical e Inteligências Múltiplas) seriam uma ponte entre as epistemologias da posse e da prática. Se de um lado ainda prevalecem algumas taxonomias e o aspecto individual do conhecimento, por outro lado as relações sociais começam a ser valorizadas em processos de aprendizagens, abrindo perspectivas para novas formas customizadas de aprendizado e construção de conhecimentos (MATTOS, 2005; GARDNER, 2001; TRAVASSOS, 2001).

Por fim, a Teoria Construtivista se assemelha à epistemologia da prática ao propor que o conhecimento não se "transfere", ele se constrói a partir da interação do indivíduo com o meio através de relações sociais. 0 sujeito sai de uma perspectiva passiva para assumir uma postura ativa e interacionista, onde não há sujeito sem objeto e nem objeto sem sujeito que o construa (SILVEIRA, 2004; VIGOTSKY, 1988). Nesta perspectiva, a aprendizagem organizacional assume uma conversação aberta entre indivíduos, por meio da participação e da reflexividade que devem ser analisadas sobre uma perspectiva multiparadigmática de saberes envolvidos (Antonello; Godoy, 2010).

A Figura 1 sintetiza os principais alinhamentos teóricos identificados entre as teorias da aprendizagem discutidas nesse ensaio teórico (Behaviorismo metodológico e radical, Teoria das Inteligências Múltiplas e Construtivismo), com as principais epistemologias da gestão do conhecimento (epistemologia da posse e da prática), introduzindo novas perspectivas de aproximação em estudos comportamentais / cognitivos da aprendizagem com a gestão do conhecimento organizacional. 
Figura 1

\section{Alinhamento de Teorias da aprendizagem na gestão do conhecimento}

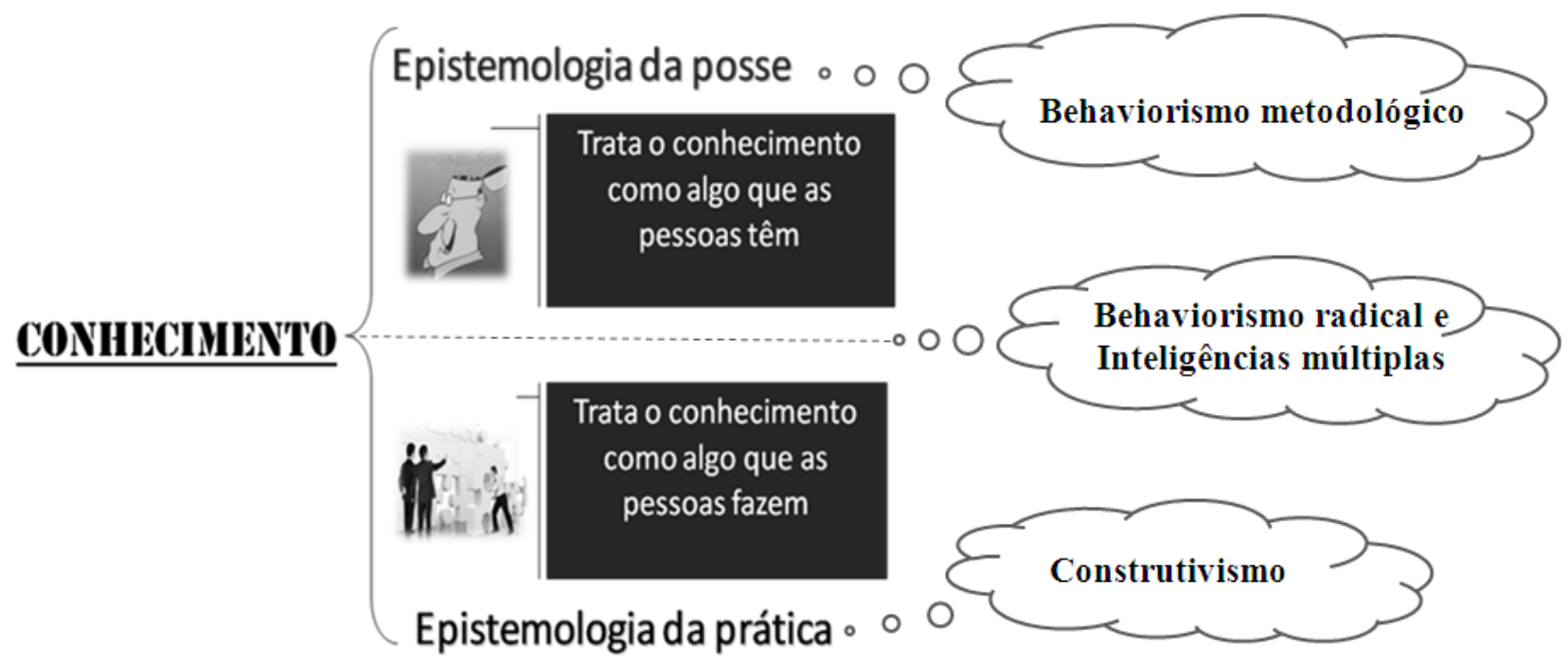

Fonte: Elaborado pelos autores

Nesse sentido, identificam-se bases epistemológicas simétricas das Teorias da aprendizagem nas epistemologias da gestão do conhecimento, surgindo dualismos entre as epistemologias da posse e da prática. De um lado de um contínuo, a perspectiva da posse e sua dimensão funcionalista considera o conhecimento como algo mensurável, possível de ser controlado e transferido, como defendido pela Teoria Behaviorista metodológica. Do outro lado de um contínuo, situa-se a epistemologia da prática, tratando o conhecimento como algo que as pessoas fazem por meio da experimentação, estando fortemente relacionada à Teoria Construtivista e sua relação de aprendizagem dinâmica através da prática social. Como pontos de divergências e convergências epistemológicas situam, entre esses dois contínuos, o Behaviorismo radical e a Teoria das Inteligências Múltiplas, ao considerar alguns pressupostos da epistemologia da posse (passividade do sujeito, estruturas cognitivas préestabelecidas), sem, no entanto, desconsiderar a importância do meio na construção de conhecimentos.

\section{Considerações finais}

Esse estudo permitiu estabelecer uma investigação entre os pressupostos das teorias da aprendizagem (Behaviorismo, Inteligências Múltiplas e Teoria Construtivista) e as relações de simetria com as epistemologias da posse e da prática presentes na literatura sobre gestão do conhecimento.

Inicialmente, concluímos que os gestores e estudiosos aderentes da epistemologia da posse, compartilham dos pressupostos da Teoria Behaviorista, ao valorizarem modelos funcionais de previsão e controle do conhecimento na mente humana. 0 conhecimento é visto como algo estocável e transmissível, independente do contexto ou do sujeito, cuja preocupação central 


\section{TEORIAS DA APRENDIZAGEM E GESTÃO DO CONHECIMENTO: UM ALINHAMENTO TEÓRICO}

está centrada na promoção de estímulos externos por meio de processos de conversão entre conhecimentos tácitos e explícitos (Neufeld; Brust; Stein, 2011; BUENO, 2011; SOUZA-SILVA; DAVEL, 2007; NONAKA; TAKEUCHI, 1997; ABREU, 1988).

Já os gestores e estudiosos aderentes à epistemologia da prática tendem a compartilhar dos pressupostos da Teoria Construtivista, ao considerarem os processos de aprendizagem altamente dependentes do contexto e das relações sociais entre indivíduos. 0 foco deixa de serem as ferramentas e os processos estruturais para valorizar o próprio indivíduo e sua relação indissociável com o meio. Assim, o conhecimento não pode ser transmissível, e sim construído pelo próprio indivíduo através de ações, práticas e interações sociais (ANTONELLO; GODOY, 2010; CAMILLIS; ANTONELLO, 2010; NEWELL et al., 2009; SOUZASILVA; DAVEL, 2007; STANO; LEITE, 2001; APPLEFIELD; HUBER; MOALLEM, 2000; VIGOTSKY, 1988).

Por fim, visando minimizar o dualismo existente entre as epistemologias da posse e da prática, percebe-se que a Teoria das Inteligências Múltiplas, assim como a Teoria do Behaviorismo radical situam-se numa faixa teórica intermediária, buscando combinar pressupostos da posse (conhecimento como algo que as pessoas têm), com pressupostos da prática (dependente do meio para se desenvolver), valorizando as competências inatas dos indivíduos, sem desconsiderar a importância de contextos particulares para ativar diversas estruturas cognitivas do conhecimento que levam à aprendizagem organizacional (NORUZI; RAHIMI, 2010; ÖZDEMIR; GÜNEYSU; TEKKAYA, 2006; GARDNER, 2001).

Dessa forma, conhecer os aspectos comportamentais e cognitivos do conhecimento pode ser útil para que, gestores e pesquisadores, compreendam as dualidades existentes nas epistemologias da posse e da prática, contribuindo para a ampliação dos debates sobre os diferentes processos que levam à aprendizagem.

Diante dos alinhamentos apresentados, espera-se ter despertado uma reflexão teórica sobre os processos da aprendizagem, demonstrando correntes e autores que contribuem para a identificação de novas formas de tornar as organizações aprendentes, não apenas de conhecimentos, mas aprendentes sobre as diferentes formas capazes de reinventar os novos processos criativos e organizacionais. Assim, espera-se que se possa defender certa "evolução" das teorias no que diz respeito ao conhecimento ser tratado de algo mais estático para algo mais dinâmico, contribuindo para explicar os processos de criação e difusão do conhecimento.

Ademais, cabe ressaltar que esse estudo apresenta algumas limitações, ao abordar parcialmente a interferência das teorias da aprendizagem nas epistemologias da gestão do conhecimento, o qual sugerem-se novas investigações (teóricas e/ou empíricas) abordando a relação de outras teorias da aprendizagem na gestão do conhecimento, seja em processos de criação, formas de aprendizado ou desenvolvimento de competências organizacionais capazes de aferir maior cientificidade aos resultados apresentados. 


\section{Referências}

ABREU, J. Notas sobre os fundamentos do Behaviorismo. Psicologia: teoria e pesquisa, v. 4, n. 2, p. 129-136, 1988.

ACKOFF, R. L. From data to wisdom. Presidential address to ISGSR, June 1988. Journal of Applied Systems Analysis, v. 16, n. 1, p. 3-9, 1989.

Antonello, C. S.; Godoy, A. S. A Encruzilhada da Aprendizagem Organizacional: uma Visão Multiparadigmática. Revista de Administração Contemporânea, Curitiba, v. 14, n. 2, art. 7, p. 310-332, 2010.

APPLEFIELD, J. M.; HUBER, R. L.; MOALLEM, M. Constructivism in Theory and Practice: Toward a Better Understanding. High School Journal, v. 82, n. 2, 2000.

ARGYRIS, C.; SHON, D. Organizational Learning. London, Addison-Wesley, 1978.

BLACKLER, F. Knowledge, knowledge work and organizations: an overview and interpretation. Organization Studies, v. 6, 1995.

BEHR, R. R.; NASCIMENTO, S. P. A gestão do conhecimento como técnica de controle: uma abordagem crítica da conversão do conhecimento tácito em explícito. Cadernos Ebape, v. 6, n.1, 2008.

BINOTTO, E. Criação de conhecimentos em propriedades rurais no Rio Grande do Sul, Brasil e em Queensland, Austrália. 2005. 261p. Tese (Doutorado em Agronegócio) Universidade Federal do Rio Grande do Sul, Porto Alegre, 2005.

BUENO, R. Los eventos privados: del conductismo metodológico al interconductismo. Universitas Psychologica, v. 10, n. 3, p. 949-962, 2011.

CAMILLIS, P. K.; ANTONELLO, C. S. Um Estudo sobre os processos de aprendizagem dos trabalhadores que não exercem função gerencial. RAM, v. 11, n. 2, p. 4-42, 2010.

CAMPOS, L. F. B. Análise da nova gestão do conhecimento: perspectivas para abordagens críticas. Perspectivas em Ciências da Informação, v. 12, n. 1, p. 104-122, 2007.

CASTAÑEDA, D. I.; RÍOS, M. F. Validación de una escala de niveles y condiciones de aprendizaje organizacional. Universitas Psychologica, n. 2, p. 245-254, 2007.

COOK, S. D. N.; BROWN J. S. Bridging Epistemologies: The Generative Dance Between Organizational Knowledge and Organizational Knowing. Organization Science, v. 10, n. 4, p. 381-400, 1999.

CÓRIA-SABINI, M. A. Psicologia aplicada à educação. São Paulo: Editora Pedagógica e Universitária, 1986.

CYERT, R. M.; MARCH, J. G. Behavioral Theory of the firm. Englewood Cliffs, N. J.: PrenticeHall, 1963.

DAVENPORT, T. H.; PRUSAK, L. Conhecimento empresarial: como as organizações gerenciam o seu capital intelectual. Tradução: Lenke Peres, Rio de Janeiro: Elsevier, 2003.

FELDMAN, M. S. ORLIKOWSKI, W. J. Theorizing Practice and Practicing Theory. 


\section{TEORIAS DA APRENDIZAGEM E GESTÃO DO CONHECIMENTO: UM ALINHAMENTO TEÓRICO}

Organization Science, 2011.

FIALHO, F. A. P.; MACEDO M.; SANTOS, N.; MITIDIERI, T. C. Gestão do conhecimento e aprendizagem: as estratégias competitivas da sociedade pós-industrial. Florianópolis: Visual Books, 2006.

FRUTUOSO, J. T.; CIRINO, S. D. A aplicação dos princípios do comportamento em contextos abertos. Revista de Ciências Humanas, n. 40, p. 339-360, 2006.

GARVIN, D. A.; EDMONDSON, A. C.; GINO, F. Is yours a learning organization? Harvard Business Review, v. 86, n. 3, 2008.

GARDNER, H. Inteligência: Um conceito reformulado. Rio de janeiro: Objetiva, 2001.

The Complete Tutor. Technos: Quarterly for Education and Technology, v. 9, n. 3, p.10-13, 2000.

Mattos, C. P. Inteligências Múltiplas: Possibilidades para o mundo do trabalho. 2005. 43 p. Trabalho de Conclusão de Curso (MBA) - Universidade Federal de Itajubá, Itajubá, 2005.

McADAM, R.; MCCREEDY, S. A critical review of knowledge management models. The Learning Organization, v. 6, n. 3, p. 91-101, 1999.

MCINERNEY, C. Knowledge management and the dynamic nature of knowledge. Journal of the American Society for Information Science and Technology, v. 53, n. 12, p. 1009-1018, 2002.

NEUFELD, C. B.; BRUST, P. G.; STEIN, L. M. Bases Epistemológicas da Psicologia Cognitiva Experimental. Psicologia: Teoria e Pesquisa, v. 27, n. 1, p. 103-112, 2011.

NEWELL, S.; ROBERTSON, M., SCARBROUGH, H.; SWAN, A. J. Managing knowledge work and innovation. $2^{\text {a }}$. Edition. London: Palgrave/Macmillan, 2009.

NONAKA, I. The knowledge-creating company. Harvard Business Review, v. 85, n. 7-8, 2007.

NONAKA, I.; KOONNO, N. The concept of "Ba": building a foundation for knowledge creation. California Management Review, v.40, n.3, p. 40-54, 1998.

NONAKA, I.; TAKEUCHI, H. Criação de conhecimento na empresa: como as empresas japonesas geram a dinâmica da inovação. Rio de Janeiro: Campus, 1997.

NORUZI, M. R.; RAHIMI, G. R. Multiple intelligences, a new look to organizational effectiveness. Journal of Management Research, v. 2, n. 2, p. 1-15, 2010.

ÖZDEMIR, P.; GÜNEYSU, S.; TEKKAYA, C. Enhancing learning through multiple intelligences. Educational Research, v. 40, n. 2, p. 74-78, Spring 2006.

PEDRAJA-REJAS, L.; RODRIGUEZ-PONCE, E. Leadership styles, knowledge management and strategy design: An empirical study in small and medium-sized firms. Interciencia, v. 33, n. 9, p. 651-657, 2008.

RECKWITZ, A. Toward a Theory of Social Practices: A Development in Culturalist Theorizing. European Journal of Social Theory. Sage Publications: Londres, p. 243-263, 2002. 
ROSAS, F. W.; MACHADO, L. R.; HWAS, R.; TORRES, T.; BEHAR, P. A. Uma proposta de objeto de aprendizagem utilizando a teoria das inteligências múltiplas. Revista Novas Tecnologias na Educação, v. 7, n. 1, 2009.

SENGE, P. M. A quinta disciplina: arte e prática da organização que aprende. Tradução: Gabriel Zide Neto, 26ํㅜ ed. Rio de Janeiro: BestSeller, 2010.

SILVEIRA, A. A. Gestão do conhecimento com ênfase na aprendizagem organizacional: Um estudo multicaso no contexto bancário. 2004. 187 p. Dissertação (Mestrado em Engenharia da Produção) - Universidade Federal de Itajubá, Itajubá, 2004.

SKINNER, B. F. Ciência e comportamento humano. São Paulo: Martins Fontes, 2000.

SOUZA-SILVA, J. C.; DAVEL, E. Da ação à colaboração reflexivas em comunidades de prática, Revista de Administração de empresas, p. 53-65, 2007.

SPENDER, J. C. Organizational knowledge, learning and memory: three concepts in search of a theory. Journal of Organizational Change Management, v. 9, n.1, p. 63-78, 1996.

STANO, R. C. M. T; Leite, V. F. A Teoria da gestão do conhecimento sob um olhar construtivista. In: Anais do 4ํo Simpósio Internacional de Gestão de Documentos. Curitiba, 2001.

SVEIBY, K. E. A nova riqueza das organizações. Rio de Janeiro: Campus. 1998.

SWAN, J.; NEWELL, S.; SCARBROUGH, H.; HISLOP, D. Knowledge management and innovation: networks and networking. Journal of Knowledge Management, v. 3, n. 4, p. 262-275, 1999.

TAVARES, W. R. Gestão do Conhecimento, Educação e Sociedade do Conhecimento. São Paulo: Ícone, 2010.

Travassos, L. C. P. Inteligências múltiplas. Revista de Biologia e Ciências da Terra, v. 1, n. 2, 2001.

VIGOTSKY L. Pensamento e Linguagem. São Paulo: Martins Fontes, 1988. 